\title{
To Compare the Frequency of Chlamydial Infection in Infertile Women Compared to Normal Women
}

\author{
SALMA JABEEN ${ }^{1}$, SHAKILA YASMIN ${ }^{2}$, SHUMAILA RIAZ ${ }^{3}$, AISHA NAZEER $^{4}$ \\ ${ }^{1}$ Associate Professor OBGY Department, Quaid-e-Azam medical college (QAMC) Bahawalpur \\ ${ }^{2}$ Professor OBGY Department, QAMC Bahawalpur \\ ${ }^{3} O B G Y$ department, QAMC Bahawalpur \\ ${ }^{4} O B G Y$ Department, \\ ${ }^{5}$ Assistant Professor OBGY department QAMC Bahawalpur \\ Correspondence to: Dr. Salma Jabeen,Ph no: 03027874800,Email: salmajabeen.2576@yahoo.com
}

\begin{abstract}
Background: A better understanding of the role of persistent $\mathrm{C}$. trachomatis infections in tubal factor subfertility may be useful in optimizing the fertility work-up by incorporating screening tests for persistent C. trachomatis infections. The aim is to accurately estimate the risk of persistence and identify those women who are at highest risk of tubal pathology.

Aim: To compare the frequency of chlamydial infection in infertile women compared to normal women.

Study Design: Case control study.

Settings: Department of Obstetrics \& Gynecology, Hospital, Bahawalpur.

Study duration: $1^{\text {st }}$ October 2019 to $31^{\text {st }}$ March 2020.

Methods: A total of 88 women (44 infertile and 44 normal), having normal semen analysis report, of age ranging from 18 to 40 years were included. Patients with polycystic ovarian disease, hyperprolactinemia, \& hypothyroidism were excluded. Blood sample of all women in both groups was sent to the institutional pathology laboratory for presence or absence of chlamydial infection.

Results: The mean age of women in case group was $27.80 \pm 3.60$ years and in control group was $28.05 \pm 3.69$ years. The mean duration of marriage in case group was $4.93 \pm 1.66$ years and in control group was $4.95 \pm 1.68$ years. The mean BMl in case group was $29.36 \pm 2.52 \mathrm{~kg} / \mathrm{m} 2$ and in control group was $29.50 \pm 2.51 \mathrm{~kg} / \mathrm{m} 2$. My study reveals the frequency of chlamydial infection in infertile women was seen in 15 (34.09\%) women as compared to $05(9.09 \%)$ in normal women which has shown p-value of 0.007 and odds ratio of 5.17 which is significant.

Conclusion: This study concluded that frequency of chlamydial infection in infertile women is higher compared to normal women.

Keywords: Infertility, chlamydial infection, tubal factor, sexually transmitted diseases
\end{abstract}

\section{INTRODUCTION}

The one of most important life plans of young couples is to become parent. In different social \& cultural backgrounds, motherhood is still a beautiful and different aspect of life increasing the responsibilities for the couples. ${ }^{1}$

The inability to achieve pregnancy within 1 year, of sexually active couples taking no contraceptives defines infertility. ${ }^{2}$ If a couple never has been able to conceive it is termed as primary infertility. While the term secondary infertility refers to couples who are unable to conceive after becoming pregnant once (at least) ${ }^{3}$ One couple out of six, need medical advice to conceive. The current global infertility rate is around about $15 \%$. Sexually transmitted infections (STI) are considered as one of preventable cause of infertility across the globe, because they can lead to pelvic inflammatory disease (PID) resulting in tubal block. ${ }^{4,5}$ The bacterium: Chlamydia trachomatis (C.T) leading to genital tract Chlamydial infection, is one of most commonly identified STI. ${ }^{6}$

Chlamydia trachomatis leads to acute genital tract infections in both men \& women. This lead to acute urethral syndrome, cervicitis, salpingits and endometritis in females \& urethritis, epididymitis \& proctitis in males. ${ }^{7}$ If optimal and

Received on 03-01-2021

Accepted on 13-05-2021 in time medical intervention done, these infections can be cured \& controlled. Sub optimal treatment may lead to increase in morbidity of sufferers like pelvic inflammatory disease (PID), chronic pelvic pain, ectopic pregnancy and tubal factor infertility. Many studies have shown a strong correlation between tubal factor infertility \& with the presence of serum antibodies against C. trachomatis, leading to infertility. ${ }^{8} \mathrm{~A}$ better knowledge of the persistent C. trachomatis infections ( resulting in tubal factor subfertility) may be helpful in improving the fertility work-up. We can identify those women who are at high risk of tubal pathology by including screening for persistent C. trachomatis infections. ${ }^{8-10}$ A study, pointed out significant difference in both groups: that $30 \%$ of infertile women had anti-chlamydial IgG in their serum, in contrary to $6.66 \%$ of fertile women .11

Study mentioned above has shown the correlation of chlamydia trachomatis infection and infertility but the available data on this is very scarce, so the rationale of this research was to determine the frequency of chlamydial infection in infertile women compared to normal women in local population. Although previously many international studies are available on this but lacking local data regarding it, so my study will provide the local stats on this for evaluation of the infertile women. 


\section{MATERIALS \& METHODS}

This Case control study was conducted at department of Gynecology and Obstetrics, Bahawalpur from 1st October 2019 to 31 March 2020. Non-probability, consecutive sampling method was used to take sample size of 88 (44 in each group)

Women coming to outpatient department of age 18-40 years having normal male factor (normal semen analysis report) were enrolled for the study. Two groups (Case and control group) were made. They were defined as following: case group/infertility group: was defined as inability to conceive for at least one year of unprotected intercourse and was included both i.e. primary and secondary infertility. Control group/normal pregnant women: all healthy women visiting the antenatal clinic during this duration was taken. Presence of serum anti-chlamydial IgG antibodies on ELISA was taken as positive case of Chlamydial infection. The women with Hyperprolactinemia (prolactin levels $>500$ $\mathrm{mIU} /$ ), Hypothyroidism (presence of all these; $\mathrm{TSH}>5.2$ $\mathrm{mIU} / \mathrm{L}$ and FT3 $<1.5 \mathrm{pg} / \mathrm{ml}$, FT4 $<0.8 \mathrm{pg} / \mathrm{ml}$, T3 $<70 \mathrm{ng} / \mathrm{dl}$, T4 $<5.2 \mu \mathrm{g} / \mathrm{dl}$ ), polycystic ovarian syndrome, were excluded. Patient having history of intake of antibiotic within last two months were also not enrolled

Hypothesis: Frequency of chlamydial infection in infertile women is higher compared to normal women.

Data Collection Procedure: Total 88 women fulfilling the inclusion criteria presented in OPD of Department of Obstetrics \& Gynecology, QAMC Bahawalpur were selected. Written informed consent was taken from the all women. In group A, 44 women with infertility (as peroperational definition) was taken while in group $B, 44$ healthy female attendants of same age groups and other demographic features were taken. Blood sample of all women in both groups was sent to the institutional pathology laboratory for presence or absence of chlamydial infection (as per-operational definition). All the information (age, duration of marriage, BMI, diabetes mellitus, hypertension) was collected on the specially designed performa.
Statistical analysis: All the data was entered and analyzed by using SPSS version 22.0. Mean and standard deviation were presented for age, duration of marriage and BMI. Qualitative variables like diabetes mellitus (yes/no), hypertension (yes/no), and chlamydial infection (present/absent) were presented by frequency and percentages. Comparison between the groups with respect to chlamydial infection was analyzed by Chi-square test and $p$ value $\leq 0.05$ was considered as statistically significant. Odds ratio was also calculated and $>1$ was taken as significant.

Effect modifiers were controlled by stratification of data regarding age, duration of marriage, BMI, diabetes mellitus, hypertension. Post-stratification chi-square was applied to see the effect of these on chlamydial infection and $p$-value $\leq 0.05$ was taken as significant. Odds ratio was also calculated and $>1$ was taken as significant.

\section{RESULTS}

Most of the study population's age range was from 18 to 40 years with mean age of $27.92 \pm 3.62$ years. The mean age of women in case group was $27.80 \pm 3.60$ years and in control group was $28.05 \pm 3.69$ years. Majority of the patients $57(64.77 \%)$ were between 18 to 30 years of age as shown in Table I.

The mean duration of marriage in case group was $4.93 \pm 1.66$ years and in control group was $4.95 \pm 1.68$ years as shown in Table I. The mean BMI in case group was $29.36 \pm 2.52 \mathrm{~kg} / \mathrm{m}^{2}$ and in control group was $29.50 \pm$ $2.51 \mathrm{~kg} / \mathrm{m}^{2}$ as shown in Table I. Distribution of patients according to diabetes mellitus and hypertension is also shown in Table I. My study reveals the frequency of chlamydial infection in infertile women was seen in 15 (34.09\%) women as compared to 05 (9.09\%) in normal women as shown in Figure I, which has shown p-value of 0.007 and odds ratio of 5.17 which is significant.

Stratification of chlamydial infection with respect to age groups, duration of marriage, BMI, diabetes mellitus and hypertension is shown in Table II.

Table-I:

\begin{tabular}{|c|c|c|c|c|c|c|}
\hline \multirow[t]{2}{*}{ Age (years) } & \multicolumn{2}{|l|}{ Cases $(n=44)$} & \multicolumn{2}{|l|}{ Controls $(n=44)$} & \multicolumn{2}{|l|}{ Total $(\mathrm{n}=88)$} \\
\hline & No. of patients & \%age & No. of patients & \%age & No. of patients & \%age \\
\hline $18-30$ & 30 & 68.18 & 27 & 61.36 & 57 & 64.77 \\
\hline $31-40$ & 14 & 31.82 & 17 & 38.64 & 31 & 35.23 \\
\hline Mean \pm SD & \multicolumn{2}{|l|}{$27.80 \pm 3.60$} & \multicolumn{2}{|l|}{$28.05 \pm 3.69$} & \multicolumn{2}{|l|}{$27.92 \pm 3.62$} \\
\hline \multicolumn{7}{|c|}{ Duration (years)of marriage } \\
\hline$\leq 5$ & 26 & 59.09 & 25 & 56.82 & 51 & 57.95 \\
\hline$>5$ & 18 & 40.91 & 19 & 43.18 & 37 & 42.05 \\
\hline Mean \pm SD & \multicolumn{2}{|l|}{$4.93 \pm 1.66$} & \multicolumn{2}{|l|}{$4.95 \pm 1.68$} & \multicolumn{2}{|l|}{$4.94 \pm 1.66$} \\
\hline \multicolumn{7}{|l|}{ BMI $\left(\mathrm{kg} / \mathrm{m}^{2}\right)$} \\
\hline$\leq 27$ & 12 & 27.27 & 13 & 29.55 & 25 & 28.41 \\
\hline$>27$ & 32 & 72.73 & 31 & 77.45 & 63 & 71.59 \\
\hline Mean \pm SD & \multicolumn{2}{|l|}{$29.50 \pm 2.51$} & \multicolumn{2}{|l|}{$29.36 \pm 2.52$} & \multicolumn{2}{|l|}{$29.43 \pm 2.50$} \\
\hline \multicolumn{7}{|c|}{ Diabetes Mellitus } \\
\hline Yes & 14 & 31.82 & 13 & 29.55 & 27 & 30.68 \\
\hline No & 30 & 68.18 & 31 & 77.45 & 61 & 69.32 \\
\hline \multicolumn{7}{|c|}{ Hypertension } \\
\hline Yes & 09 & 20.45 & 09 & 20.45 & 18 & 20.45 \\
\hline No & 35 & 79.55 & 35 & 79.55 & 70 & 79.55 \\
\hline
\end{tabular}


Figure I: Frequency of chlamydial infection in infertile women compared to normal women.

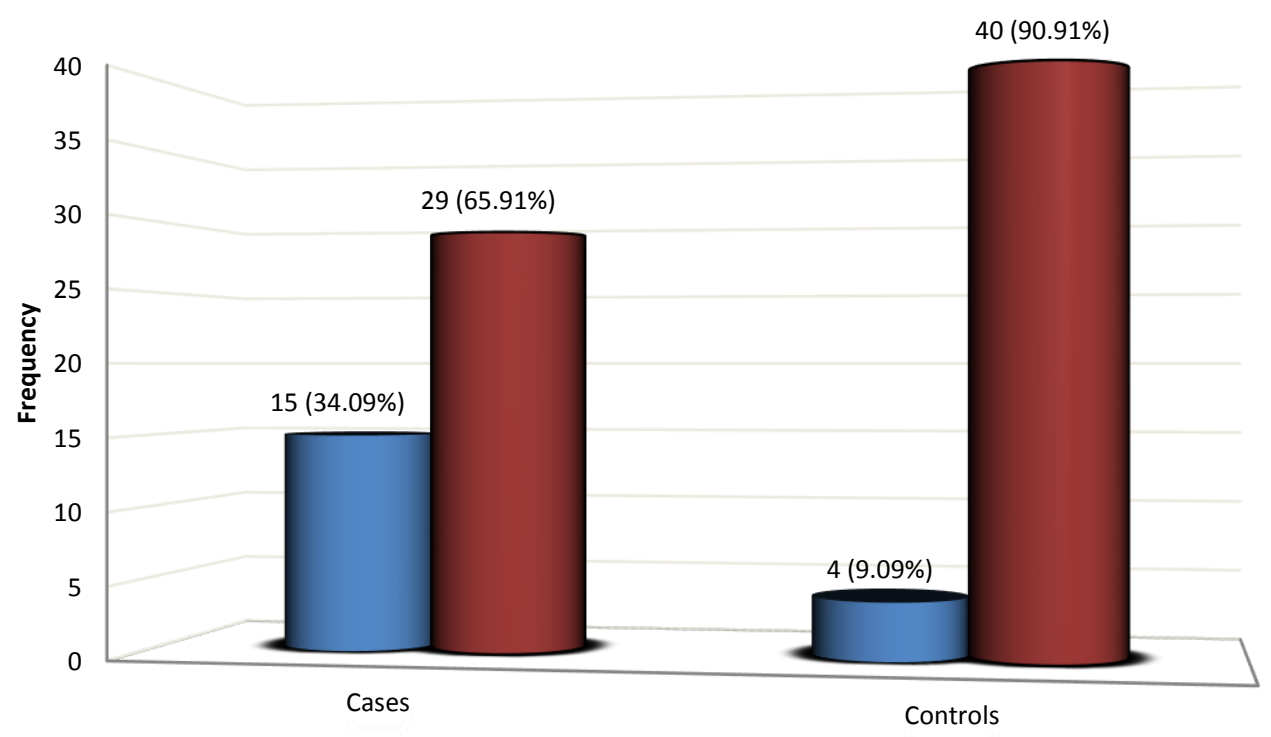

P-value 0.007 which is statistically significant.

$>$ Relative risk is 5.17 which is significant.

Table II: Stratification of chlamydial infection with respect to age groups.

\begin{tabular}{|c|c|c|c|c|c|c|}
\hline \multirow{3}{*}{ Age of patients (years) } & \multirow{2}{*}{\multicolumn{2}{|c|}{$\begin{array}{l}\text { Cases ( } n=44) \\
\text { Chlamydial infection }\end{array}$}} & \multirow{2}{*}{\multicolumn{2}{|c|}{$\begin{array}{l}\text { Controls }(n=44) \\
\text { Chlamydial infection }\end{array}$}} & \multirow{3}{*}{ P-value } & \multirow{3}{*}{ OR } \\
\hline & & & & & & \\
\hline & yes & no & yes & no & & \\
\hline $18-30$ & 10 & 20 & 02 & 25 & 0.027 & 6.25 \\
\hline $31-40$ & 05 & 09 & 02 & 15 & 0.128 & 4.17 \\
\hline \multicolumn{7}{|c|}{ Duration of marriage (years) } \\
\hline$\leq 5$ & 09 & 17 & 03 & 22 & 0.067 & 3.88 \\
\hline$>5$ & 06 & 12 & 01 & 18 & 0.05 & 9.00 \\
\hline \multicolumn{7}{|l|}{ BMI $\left(\mathrm{kg} / \mathrm{m}^{2}\right)$} \\
\hline$\leq 27$ & 04 & 08 & 02 & 11 & 0.067 & 3.88 \\
\hline$>27$ & 11 & 21 & 02 & 29 & 0.05 & 9.00 \\
\hline \multicolumn{7}{|l|}{ Diabetes mellitus } \\
\hline Yes & 05 & 09 & 01 & 12 & 0.108 & 6.67 \\
\hline No & 10 & 20 & 03 & 28 & 0.03 & 4.67 \\
\hline \multicolumn{7}{|l|}{ Hypertension } \\
\hline Yes & 03 & 06 & 00 & 09 & 0.145 & 10.23 \\
\hline No & 12 & 23 & 04 & 31 & 0.03 & 4.04 \\
\hline
\end{tabular}

\section{DISCUSSION}

Many factors are attributed as a cause for infertility. If all the standard investigations for example semen analysis, tests for ovulation, \& tubal patency are normal, then it is labeled as unexplained infertility (UI). ${ }^{12}$ Genital tract infections play a major role in causation of infertility especially 2ndry infertility. Chlamydia trachomatis, a bacterial pathogen is mostly identified as a leading sexually transmitted infection. ${ }^{13}$ Approximately 90 million women acquire it annually worldwide, making it a major burden on public health. The developing countries, where the facilities for diagnosis and treatment are already negligible, have to bear the main burden of disease $\left(>2 / 3^{\text {rd }} \text { of cases }\right)^{14}$ Majority of population remain asymptomatic after being infected with C.trachomatis. These $50-70 \%$ of infected women remain symptoms free so could not diagnosed \& managed, leading to serious long-term squeal, such as chronic pelvic pain, tubal infertility, \& ectopic pregnancy. ${ }^{15,16}$ To decrease the period of infectivity, transmission and long term sequelae caused by $\mathrm{C}$. trachomatis, screening is required to pick out and treat it.

I have conducted this study to compare the frequency of chlamydial infection in infertile women compared to normal women. Age range in my study was from 18 to 40 years Majority of the patients $57(64.77 \%)$ were between 18 to 30 years of age. These results are similar to a study conducted in Eithopia in which highest prevalence of CT infection (24.2\%), was seen in women aged 15-24 years, followed by $16.8 \%$ in aged $25-34$ years and $9 \%$ only, in aged 35-49 years. ${ }^{17}$ Another recent research also noted high CT infection among young women. it pointed out that the most infertile women were of $31-35$ years, \& the primary infertility with the most common type (83\%) with the longest infertility duration was 3 years (44\%). $26 \%$ of infertile women were detected to be screen positive for chlamydia infection. 8 women out of 12 women (66\%), who were $\mathrm{CT}+\mathrm{ive}$, diagnosed to have blocked fallopian tubes 
with $\mathrm{p}$-value $=0.001$ which is suggestive of a strong correlation between Chlamydia Trachomatis infection with tubal patency in infertile women. ${ }^{18}$

My study reveals the frequency of chlamydial infection in infertile women was seen in 15 (34.09\%) women as compared to $05(9.09 \%)$ in normal women which has shown p-value of 0.007 and odds ratio of 5.17 which is significant. The findings of my study were strengthened a by similar results found in a research work conducted by EL-Guindy $A$ that showed, among infertile women,30\% women had positive serum anti chlamydial lgG, while only $6.66 \%$ women of the control group screened positive. The difference was significant between both groups. ${ }^{11}$

As majority of cases of Genital Chlamydia infection are asymptomatic, so only few data is available regarding prevalence or incidence. ${ }^{19}$ The population-based data available from the, Australia ,United States, and the United Kingdom showed that between 3 to $5 \%$ of their population below 30 years of age will be infected with Chlamydia at any point in life. ${ }^{20-22} \mathrm{~A}$ study conducted in Mexican couples. highlighted the prevalence of infection of CT as $8.68 \%$. with $22 \%$ of concordance rate (13 couples). Estimates of the incidence of long term squeal are still lacking.

However, there is strong evidence that women who acquire Chlamydia infection develop pelvic inflammatory disease (PID) leading to infertility by blocking the tubes., A longitudinal cohort study was conducted by Weström et al. (12) to evaluate PID and fertility outcomes. This research followed 1,844 women having abnormal laparoscopic findings upon suspicion of acute PID and 657 women who had normal findings (controls). Follow-up found that among women who were trying to conceive, $16.5 \%$ of the case subjects and $2.7 \%$ of the controls failed to conceive. ${ }^{23}$ Additional workup showed that $141(10.8 \%)$ of the PID case subjects and none of the controls had tubal factor infertility (TFI). ${ }^{23}$ Moreover, the ectopic pregnancy rate was found higher $(9 \%)$ in the PID case subjects, in comparison with control group (1.4\%). ${ }^{23}$ However, this study did not identified underlying infectious agent responsible for PID. A RCT was done to assess the significance of chlamydial screening in halting the PID progression. This found that the women whose Chlamydia infections were left untreated, $9 \%$ of among them developed PID, This is significantly higher as compared to the women whose infections were treated (1.6\%). ${ }^{24}$

Many researches are agreed with finding of our observations that presence of antibodies against C. trachomatis is directly related with tubal factor infertility. Svenstrup et al. reported that $23 \%$ of women suffering from tubal factor infertility (TFI) had antibodies against $\mathrm{C}$. trachomatis, compared with $15 \%$ of women in the control group with normal tubes. ${ }^{25}$ Similarly, Siemer et al pointed out that prevalence of $\lg$ and $\lg A$ antibodies is higher among women with infertility (39\% and $14 \%$, respectively), as compared with women of the control group (19\% and $3 \%$, respectively). ${ }^{26}$ In a study carried out by Malik et al. the presence of $\mathrm{C}$. trachomatis in infertile women was $28.1 \%$, which was significantly higher than that of healthy women $(3.3 \%)(P<0.01) .{ }^{27}$

As prevalence of asymptomatic genital chlamydial infections is high in women of reproductive age, early identification of the infectious agent \& its treatment should be the aim along with limiting its transmission. ${ }^{28}$ Direct detection of Chlamydia trachomatis antigen by ELISA in clinical samples has been labeled as a relatively rapid \& simple technique. This method has good sensitivity and specificity in the diagnosis of chlamydial infections. ${ }^{29}$ Evidence exists that undetected \& untreated cervical chlamydial infection can move high up to fallopian tubes to produce silent salpingitis and infertility as its sequalae. ${ }^{29}$

\section{CONCLUSION}

This study concluded that frequency of chlamydial infection in infertile women is higher compared to normal women. So, we recommend that in every infertile woman, chlamydial infection should be taken into consideration and its early recognition and management should be done in order to reduce the long term morbidities \& to decrease the public health burden.

\section{REFERENCES}

1. Begum BN, Hasan S. Psychological problems among women with infertility problem: a comparative study. J Pak Med Assoc. 2014;64:1287.

2. Morhason-Bello I, Ojengbede O, Oladokun A, Adedokun B, Ajayi A, Adeyanju A, et al. The prevalence and outcome of asymptomatic chlamydial infection screening among infertile women attending gynecological clinic in Ibadan, South West Nigeria. Ann Med Health Sci Res. 2014;4(2):253-57.

3. Lavorato HL, Moço NP, Martin LF, Santos AGP, Pontes A Duarte MTC, et al. Screenning of chlamydia trachomatis infection among women attending outpatient clinic of infertility. Open J Obstet Gynecol. 2015;5:600-607.

4. Rashidi BH, Chamani-Tabriz L, Haghollahi F, Jeddi-Tehrani M, Naghizadeh MM, Shariat M, et al. Effects of chlamydia trachomatis infection on fertility; a case-control study. J Reprod Infertil. 2013;14:67-72.

5. Malhotra M, Sood S, Mukherjee A, Muralidhar S, Bala M. Genital chlamydia trachomatis: an update. Indian J Med Res. 2013;138:303-16.

6. Mishori R, McClaskey EL, Winklerprins VJ. Chlamydia trachomatis infections: screening, diagnosis, and management. Am Fam Physician. 2012;86:1127-32.

7. Ghosh M, Choudhuri S, Ray RG, Bhattacharya B, Bhattacharya S. Association of genital chlamydia trachomatis infection with female infertility, study in a tertiary care hospital in Eastern India. Open Microbiol J. 2015;9:11016.

8. Dhawan B, Rawre J, Ghosh A, Malhotra N, Ahmed MM Sreenivas $V$, et al. Diagnostic efficacy of a real time PCR assay for chlamydia trachomatis infection in infertile women in North India. Indian J Med Res. 2014;140:252-61.

9. Nwankwo EO, Sadiq MN. Prevalence of chlamydia trachomatis infection among patients attending infertility and sexually transmitted diseases clinic (STD) in Kano, North Western Nigeria. Afr Health Sci. 2014;14:672-78.

10. Marashi SMA, Moulana Z, Fooladi AAI, Karim MM Comparison of genital c. trachomatis infection incidence between women with infertility and healthy women in iran using pcr and immunofluorescence methods. Jundishapur $\mathrm{J}$ Microbiol. 2014;7:1-4.

11. EL-Guindy A, Rabei N, Mohammed N, Hassan N Prevalence of the anti-chlamydial antibodies in infertile women and its association with tubal factor infertility. Int $\mathrm{J}$ Obstet Gynaecol Res. 2016;3:310-25.

12. Ray A, Shah A, Gudi A, Homburg R. Unexplained infertility: an update and review of practice. Reprod Biomed Online. 2012; 24(6):591-602. 
13. Johnson RE, Newhall WJ, Papp JR, Knapp JS, Black CM, Gift TL, et al. Screening tests to detect Chlamydia trachomatis and Neisseria gonorrhoeaeinfections-2002. MMWR Recomm Rep. 2002;51(RR-15):1-38.

14. Gaydos CA, Theodore M, Dalesio N, Wood BJ, Quinn TC. Comparison of three nucleic acid amplification tests for detection of Chlamydia trachomatis in urine specimens. J Clin Microbiol. 2004;42(7):3041-5.

15. Gonzales GF, Muñoz G, Sánchez R, Henkel R, GallegosAvila G, Díaz-Gutierrez O, et al. Update on the impact of Chlamydia trachomatis infection on male fertility. Andrologia. 2004;36(1):1-23.

16. Hu D, Hook EW, 3rd, Goldie SJ. Screening for Chlamydia trachomatis in women 15 to 29 years of age: a costeffectiveness analysis. Ann Intern Med. 2004;141(7):501-13.

17. Tadesse E, Teshome M, Amsalu A, Shimelis T. Genital Chlamydia trachomatis Infection among Women of Reproductive Age Attending the Gynecology Clinic of Hawassa University Referral Hospital, Southern Ethiopia. (2016) PLOS ONE 11(12): e0168580. https://doi.org/10.1371/journal.pone.0168580

18. Sukatendel K, Mayniar TE, Aboet A, Adela CA, Lumbanraja S, Ichsan TM, Edianto D. Relationship between Chlamydia Trachomatis Infection with Patency Tubal and Non-Patency Tubal Occurrence in Infertile Women. OA mjms. 2019, 7 (20) :3437-42.

19. Peipert JF. Clinical practice. Genital chlamydial infections. N Engl J Med 2003;349:2424 -2430.

20. Lewis D, Newton DC, Guy RJ, Ali H, Chen MY, Fairley CK, Hocking JS. The prevalence of Chlamydia trachomatis infection in Australia: a systematic review and meta-analysis. BMC Infect Dis 2012;12:113.

21. Datta SD, Torrone E, Kruszon-Moran D, Berman S, Johnson $\mathrm{R}$, Satterwhite $\mathrm{CL}$, et al. Chlamydia trachomatis trends in the
United States among persons 14 to 39 years of age, 1999 2008. Sex Transm Dis 2012;39:92-96.

22. Price MJ, Ades AE, de Angelis D, Welton NJ, Macleod J, Turner K, Horner PJ. Incidence of Chlamydia trachomatis infection in women in England: two methods of estimation. Epidemiol Infect 2014;142:562-576.

23. Weström L, Joesoef R, Reynolds G, Hadgu A, Tompson SE. Pelvic inflammatory disease and fertility. A cohort study of 1844 women with laparoscopically verified disease and 657 control women with normal laparoscopic results. Sex Transm Dis 1992;19:185-192.

24. Oakeshott P, Kerry S, Aghaizu A, Atherton H, Hay S, TaylorRobinson D, et al. Randomised controlled trial of screening for Chlamydia trachomatis to prevent pelvic inflammatory disease: the POPI (prevention of pelvic infection) trial. BMJ 2010;340:c1642.

25. Svenstrup HF, Fedder J, Kristoffersen SE, Trolle B, Birkelund S, Christiansen G. Mycoplasma genitalium, Chlamydia trachomatis, and tubal factor infertility--a prospective study. Fertil Steril. 2008; 90(3): 513-20.

26. Siemer J, Theile O, Larbi Y, Fasching PA, Danso KA, Kreienberg $\mathrm{R}$, et al. Chlamydia trachomatis infection as a risk factor for infertility among women in Ghana, West Africa. Am J Trop Med Hyg. 2008; 78(2): 323-7.

27. Malik A, Jain S, Hakim S, Shukla I, Rizvi M. Chlamydia trachomatis infection \&amp; female infertility. Indian J Med Res. 2006; 123(6): 770-5.

28. Cates W, Wasserheit JN. Genital chlamydial infections: epidemiology and reproductive sequelae.Am $\mathrm{J}$ Obstet Gynecol. 1991;164:1771-1781.

29. Asin JD, Nahorst RR, Thijs CT, Assendelft WJ, Hooi BR. Routine testing for Chlamydia trachomatis on Curaçao, Netherlands Antilles. Am J Obstet Gynecol. 1993;169:375378. 